\section{drinking schedule'}

DOUGLAS J. NAVARICK, Rutgers University, New Brunswick, N. J. 08903 and ANDREW STROUTHES, State University of New York at Binghamton, Binghamton, N. Y. 13901

Previous data indicated that saccharinwhen thirsty. To illuminate the . ole of inexperience in this effect, wa d eprived rats were permitted $90 \mathrm{~min}$ :ess to saccharin and water daily. Initia. ', water intake equalled or exceeded saccharin intake, depending on the concentration. Subsequently, saccharin intake exceeded water intake, suggesting Ss may have adapted to an "unpalatable" component of saccharin.

Collier \& Bolles (1968) found that in water-deprived rats neither short-term consumption of sucrose solution nor rate of bar pressing for sucrose varied appreciably with sucrose concentration (4-16\%). They concluded that "in thirsty animals calorically-associated tastes became unimportant as determinants of intake [p. 639]." Findings by Strouthes \& Navarick (1967) appear to set limits on the generality of this conclusion. When water-deprived and nondeprived rats were permitted continuous access to saccharin solution (SAC) and water, water intake of deprived rats in the first $10 \mathrm{~min}$ of exposure exceeded SAC intake, while SAC intake of nondeprived rats exceeded water intake. Relative water intake over $90 \mathrm{~min}$ increased with SAC concentration and hours of deprivation.

In a continuous choice with water, therefore, a "calorically-associated taste" may affect consumption tendencies of water-deprived rats. But the nature of this effect is puzzling. Rats deprived of water "voluntarily" deprive themselves of food (e.g., Bolles, 1961). Since the reward value of "sweet tastes" increases with food deprivation (Sheffield \& Roby, 1950), any influence of SAC might reasonably be expected to be in the direction of a higher SAC than water intake.

In Strouthes \& Navarick (1967), rats were naive with respect to $S A C$ prior to exposure. The possibility thus exists that the obtained effects are peculiar to naive rats. In the present study, the experience factor was investigated by means of a water-deprivation schedule in which SAC and water were presented together or singly during exposure naive rats drink more water than saccharin periods. These methods of presentation permitted, respectively, within- and between-Ss assessment of trends in SAC and water intake.

Thirty-five Sprague-Dawley male albino rats, 220-310 days old, served as Ss.

\section{APPARATUS}

During deprivation periods Ss were housed in home cages measuring $10 \times 7 \times 7 \frac{1}{2}$ in. Drinking sessions were administered in $9 \times 10 \times 8$-in. drinking cages with backs and side walls constructed of wood. One or two Richter tubes were attached to the front of each drinking cage depending on the experimental condition. Concentrations were by weight. All solutions were mixed with deionized water.

\section{PROCEDURE}

The Ss were randomly assigned to five groups $(\mathrm{N}=7)$. Group $.1 \cdot \mathrm{H}$ received $.1 \%$ SAC and water, Group 11 a single tube of $.1 \% \mathrm{SAC}$, Group 1-H 1\% SAC and water, Group 1 a single tube of $1 \% \mathrm{SAC}$, and Group $\mathrm{H}$ a single tube of water. This arrangement continued for 14 exposure periods. In a second phase of the experiment, consisting of six periods, water tubes of Groups $.1-\mathrm{H}$ and $1-\mathrm{H}$ were withdrawn and presented to Ss in Groups .1 and 1.

The duration of exposure periods was $90 \mathrm{~min}$. Prior to Period 1 Ss were deprived of water for $24 \mathrm{~h}$. Thereafter, $22 \frac{1}{2} \mathrm{~h}$ of deprivation intervened between periods. For choice animals, the daily positions of the tubes were varied according to an ABBA design. Food was available to $S s$ in both the deprivation and drinking cages.

\section{RESULTS}

Figure 1 shows mean intake of Groups 1 , $1-\mathrm{H}$, and $\mathrm{H}$ as a function of exposure periods. In Period 1, water intake of Group 1-H exceeded SAC intake. In subsequent periods, SAC intake exceeded water intake, with SAC consumption increasing and water consumption decreasing with periods. Analysis of variance indicated a significant Substance by Periods interaction $(F=4.69, \mathrm{df}=13 / 160, \mathrm{p}<.01)$ and a significant difference in Period 1 $(F=16.40, \mathrm{df}=1 / 6, \mathrm{p}<.01) .{ }^{2} \mathrm{SAC}$ in take of Group 1 and water intake of Group H increased significantly with periods (Group H: $F=2.68, \mathrm{df}=13 / 77, \mathrm{p}<.01$; Group 1: $F=11.59, \mathrm{df}=13 / 77, \mathrm{p}<.01)$. In Periods 1 and 2 Group $H$ intake exceeded Group 1 intake, while in Periods 3 to 14 Group 1 intake exceeded Group $\mathrm{H}$ intake. Significance was obtained both for the Period 1 intake difference $(F=6.85$, $\mathrm{df}=1 / 12, \mathrm{p}<.05)$ and for the Groups by Periods interaction $(F=6.35, \mathrm{df}=13 / 154$, $\mathrm{p}<.01)$. Comparison of the SAC-water intake difference of Group 1 in Period 15 with that of Group 1-H in Period 1 indicates that successive exposures to a single tube of SAC was sufficient to reverse the intake relationship of Group 1-H.

Figure 2 gives mean in take of Groups .1, $.1-\mathrm{H}$, and $\mathrm{H}$ as a function of exposure periods. Group .1-H consumed more SAC than water in Period 1 but not significantly. As periods increased, SAC intake increased and water intake decreased. This divergence yielded a significant Substance by Periods

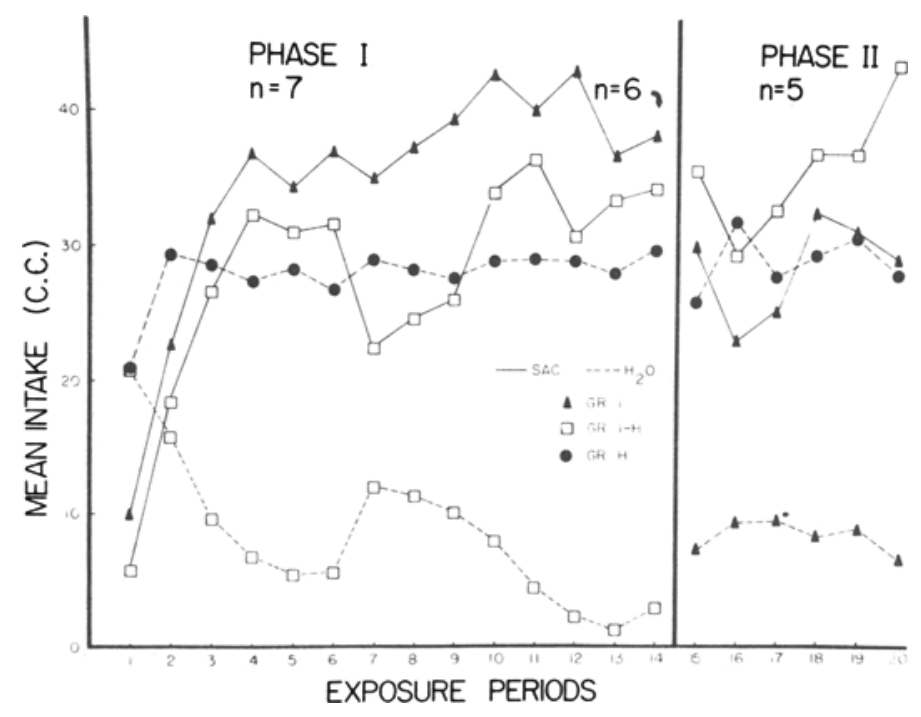

Fig. 1. Mean intake of Groups 1-H, 1, and $\mathrm{H}$ as a function of exposure periods. 


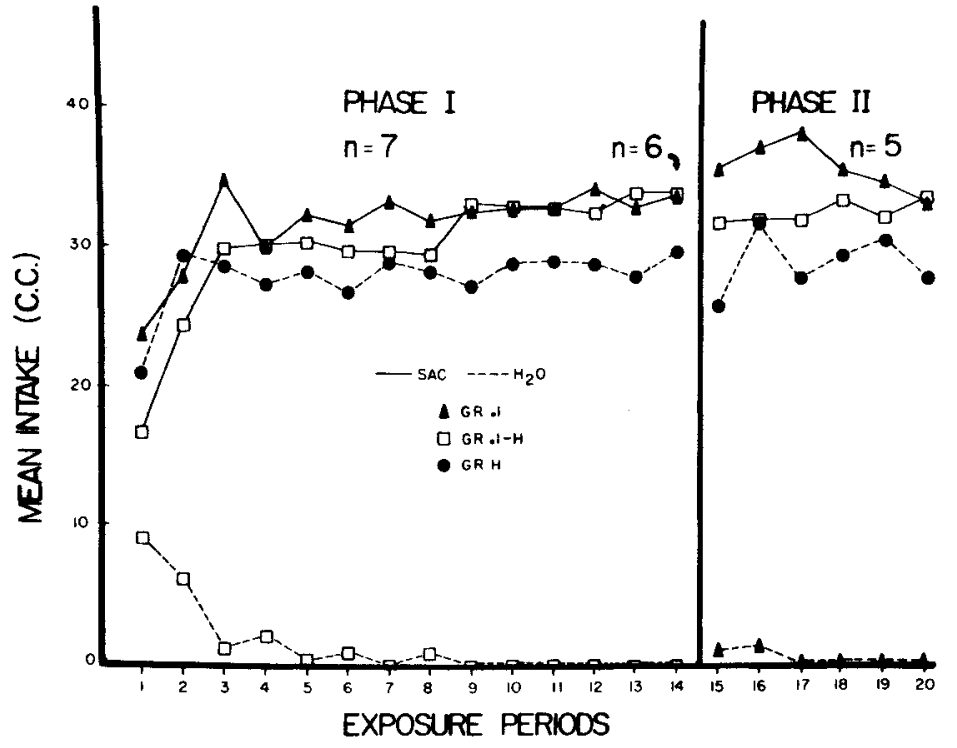

Fig. 2. Mean intake of Groups .1-H, .1, and $\mathrm{H}$ as a function of exposure periods.

interaction $(F=11.24, \quad \mathrm{df}=13 / 160$, $p<.01)$. SAC intake increased significantly with periods $(F=3.25$, $\mathrm{df}=13 / 77$, $p<.01)$. The Groups by Periods interaction was not significant. Examination of Group 1 in Period 15 reveals that exposure to a single tube of .1\% SAC had essentially the same effect on subsequent choice behavior as exposure to a single tube of $1 \% \mathrm{SAC}$, namely, to elevate relative $S A C$ intake.

Two interconcentration comparisons are noteworthy. First, relative water intake of the choice groups increased with SAC concentration. Second, a higher-SAC-thanwater intake emerged in clear fashion sooner in Group .1-H than in Group 1-H.

\section{DISCUSSION}

In food deprived rats, the reward value of a "sweet taste" is greater than in nondeprived rats (Sheffield \& Roby, 1950). To the rat which has been deprived of water (and which has deprived itself of food) SAC is a potential source of two types of reinforcing stimulation: fluidity and sweetness. That more SAC than water is ultimately consumed by water-deprived rats indicates that this potential may, under appropriate conditions, be realized. It is not clear, however, why the initial response of thirsty rats is to consume more water than SAC. One possibility is that SAC acquires an aversive taste property (e.g., bitterness) under water deprivation conditions. This view is supported by the finding of Strouthes \& Navarick (1967) that higher water than SAC intakes occurred in thirsty rats within the first $10 \mathrm{~min}$ of exposure. The immediacy of the effect suggests involvement of a gustatory mechanism. Also, the finding that less $1 \% \mathrm{SAC}$ is initially consumed from a single tube than water from a single tube (Fig. 1) would seem to indicate an aversive response.

The present hypothesis states that the aversiveness of SAC increases with concentration, but the sweetness of the substance remains sufficient to induce drinking at least up to a $1 \%$ concentration. The initial "preference" for water may be attributed to a difference in "palatability" between SAC and water, and possibly, to prior learning of an approach response to water.

Continued fluid intake conceivably initiates two processes. First, it may cause progressive reductions in thirst over days

\author{
J. J. PERSENSKY, R. J. SENTER, and R. B. \\ JONES, 2 University of Cincinnati, Cincin- \\ nati, Ohio 45221
}

The present study was an attempt to investigate the "stress reduction" theory of alcoholism thrnugh an attempt to link experimentally induced neurosis in rats with subsequent preference for alcohol. The results are in contradiction to the "stress reduction"theory.

Noting that attempts to establish compulsive alcohol consumption in laboratory rats had generally failed, Clay (1964) instituted a series of exhaustive experiments in which and thereby diminish to some extent the aversiveness of SAC. Second, continued SAC consumption may produce some form of adaptation or adjustment to the aversiveness of SAC. On this hypothesis, relative water intake would be expected to increase with concentration due to increasing intensity of the aversive component. Modification of the initial SAC-water intake relationship would be expected to occur earlier, and water intake to drop more rapidly with lower concentrations due, first, to greater effectiveness of thirst reduction, and second, to more rapid adaptation.

\section{REFERENCES}

BOLLES, R. C. The interaction of hunger and thirst in the rat. Journal of Comparative \& Physiological Psychology, 1961, 54, 580-584. COLLIER, G., \& BOLLES, R. C. Hunger, thirst and their interaction as determinan ts of sucrose consumption. Journal of Comparative \& Physiological Psychology, 1968, 66, 633-641.

SHEFFIELD, F. D., \& ROBY, T. B. Reward value of a non-nutritive sweet taste. Joumal of Comparative \& Phy siological Psy chology, 1950, 43, 471-481.

STROUTHES, A., \& NAVARICK, D. J. Sacchatine and $\mathrm{H}_{2} \mathrm{O}$ consumption as a function of $\mathrm{H}_{2} \mathrm{O}$ deprivation. Psychonomic Science, 1967, 9, 523-524.

\section{NOTES}

1. This study constituted part of an Honors project carried out by the senior author under the supervision of the junior author. A paper based on this investigation was read at the 1968 meeting of the Eastern Psychological Association, Washington, D. C.

2. Procedural difficulties forced a reduction in $N$ from seven to six in Period 14. In the following trend analyses, the indicated number of dfs was subtracted from the within-Ss error term: Group .1-H, 2; Group 1-H, 2; Group.1 vs Group H, 2; Group 1 vs Group H, 2; Groups .1, 1 , and $H, 1$ each.

\section{Alcohol consumption in rats after experimentally induced neurosis}

rats were exposed to many different situations thought to be etiologically related to alcoholism. Because of the commonly held hypothesis that alcohol consumption can reduce the detrimental effects of stress, Clay included among her experimental situations the insoluble discrimination problem (Maier, 1949) which apparently produces conflict sufficiently severe to result in the aberrant behavior known as "experimental neurosis" in rats. If the stress produced by such a circumstance is sufficient to cause severely maladaptive behavior, it would seem that animals would seek the reduction of the stress through any means available to them. Hence, if alcohol 